\title{
Differential advancement of breeding phenology in response to climate may alter staggered breeding among sympatric pygoscelid penguins
}

\author{
Heather J. Lynch ${ }^{1,4, *}$, William F. Fagan ${ }^{1}$, Ron Naveen ${ }^{2}$, Susan G. Trivelpiece ${ }^{3}$, \\ Wayne Z. Trivelpiece ${ }^{3}$ \\ ${ }^{1}$ Department of Biology, University of Maryland, College Park, Maryland 20742, USA \\ ${ }^{2}$ Oceanites, Inc., Chevy Chase, Maryland 20825, USA \\ ${ }^{3}$ Antarctic Ecosystem Research Division, NOAA/SWFSC, La Jolla, California 92038, USA \\ ${ }^{4}$ Present address: Department of Ecology \& Evolution, Stony Brook University, Stony Brook, New York 11794, USA
}

\begin{abstract}
Numerous studies link climate change with advancing breeding phenology in birds, but less frequently considered are the joint impacts on sympatrically breeding communities of birds. We used data on clutch initiation dates (CID) from 4 sites along the Western Antarctic Peninsula for 3 congeneric and sympatrically breeding penguin species (Adélie Pygoscelis adeliae, gentoo $P$. papua and chinstrap P. antarcticus) to understand what factors correlate with the phenology and synchrony of breeding and how these factors might change with the recent warming experienced in this region. We found that clutch initiation was most significantly correlated with October air temperatures such that all 3 species advanced clutch initiation to varying degrees in warmer years. Gentoo penguins were able to advance CID almost twice as much (3.2 $\left.\mathrm{d}^{\circ} \mathrm{C}^{-1}\right)$ as Adélie $\left(1.7 \mathrm{~d}^{\circ} \mathrm{C}^{-1}\right)$ and chinstrap penguins $\left(1.8 \mathrm{~d}^{\circ} \mathrm{C}^{-1}\right)$. Beyond the variation explained by mean October temperatures, there was an unexplained trend to earlier clutch initiation of 0.15 $\pm 0.05 \mathrm{~d} \mathrm{yr}^{-1}$. Greater plasticity in gentoo breeding phenology compressed the mean interval between Adélie and gentoo breeding in warm years and this may increase competition for nesting space in mixed colonies. Our results suggest that differential responses in breeding phenology to changing temperatures represent an additional mechanism by which climate change may affect competitive interactions and, consequently, pygoscelid penguins on the Antarctic Peninsula.
\end{abstract}

KEY WORDS: Breeding phenology $\cdot$ Climate change $\cdot$ Pygoscelid $\cdot$ Breeding asynchrony $\cdot$ Adélie penguin $\cdot$ Chinstrap penguin $\cdot$ Gentoo penguin $\cdot$ Interannual variability

\section{INTRODUCTION}

To understand the biological effects of climate change, scientists need to understand not only the direct effects of climate change on individual species (reviewed in Parmesan 2006), but also how changing climate may affect complex interspecific interactions (Van der Putten et al. 2010). The most frequently studied interactions are 'trophic mismatches' in which disparate phenological changes between trophic levels affect species interactions (e.g. Visser \& Both 2005 and references therein). Less frequently considered are intratrophic interactions that may be affected by climate change (exceptions include Chadwick et al. 2006, Ahola et al. 2007). Climate change can alter the relative timing of breeding and the ecological interactions among species that utilize a shared set of limited resources (food, breeding 
space, etc.). This effect may be particularly acute where migratory species co-exist with resident species, the latter of which are in a better position to respond to changing conditions at the breeding location and are therefore at a competitive advantage (Ahola et al. 2007). Although the effect of climate change on breeding phenology in birds has been considered in many studies (e.g. Brown et al. 1999, Crick \& Sparks 1999, Przybylo et al. 2000, Both et al. 2004), the subsequent impacts of these phenological changes on interspecific competition among sympatrically-breeding bird species has only recently been addressed (Schaefer et al. 2006, Ahola et al. 2007). Although imperfect, biological responses to interannual variability in climate are perhaps the best indication available of how populations might respond to long-term changes due to regional climate change (Trathan et al. 2007). Breeding synchrony among individuals in a population, although bestowing a number of potential benefits for colonially nesting seabirds (Birkhead 1977, Hatchwell 1991, Murphy \& Schauer 1996), may constrain a population from responding adequately to environmental variability (Reed et al. 2006) and, ultimately, adapting to longer-term climate change. Additionally, migration away from the breeding colony during non-breeding months may preclude a timely assessment of environmental conditions at the breeding site and thus may prevent an adequate phenological response to interannual or long-term climate change (e.g. Both \& Visser 2001, Both et al. 2006).

Few places on the planet have warmed as quickly as the Western Antarctic Peninsula (WAP) (Vaughan et al. 2003), and abundant empirical evidence links the changing climate in this region to observed changes in physical (Smith \& Stammerjohn 2001) as well as ecological systems (e.g. Croxall et al. 2002, Trathan et al. 2007, Clarke et al. 2007, Ducklow et al. 2007). Of particular interest is the impact of climate change on the WAP's 3 pygoscelid penguin species: Adélie (Pygoscelis adeliae), gentoo ( $P$. papua) and chinstrap ( $P$. antarcticus). The study of niche segregation among sympatric congeneric penguin species (e.g. Lishman 1985, Fraser et al. 1992, Lynnes et al. 2002, Wilson 2010) is complicated by the spatiotemporal heterogeneity of resources for which the species compete. Climate change introduces a dynamic element, as the ecological axes along which species are segregated adjust along with the resulting competitive relationships (Fraser et al. 1992, Croxall et al. 2002, Forcada et al. 2006). One such axis is breeding phenology, with Adélie, gentoo and chinstrap penguins breeding in sequence and over a restricted interval of $3 \mathrm{wk}$ or less (Trivelpiece et al. 1987). The staggered timing of breeding among these species may reduce the extent of direct foraging competition during chick rearing (Croxall \& Prince 1980, Lishman 1985, Trivelpiece et al. 1987), and the relative timing of arrival and nest building is an important factor for the ultimate distribution of limited snow-free nesting space, as gentoo and chinstrap penguins can outcompete Adélies for available space in mixed colonies (Trivelpiece \& Volkman 1979, Trivelpiece et al. 1984, Carlini et al. 2005, Sander et al. 2007; see also Slagsvold 1975). Despite the potential for breeding phenology to mediate competitive interactions, relatively little quantitative work has been done to understand what environmental factors are correlated with the timing of breeding in pygoscelid penguins (exceptions include Bost \& Jouventin 1990 and Barbraud \& Weimerskirch 2006), how breeding phenology varies over the spatial scale of the peninsula, or the extent to which breeding synchrony may vary between species.

Building on an earlier study to develop predictive models of clutch initiation (Lynch et al. 2009), we used data on clutch initiation dates (CIDs) for all 3 species of pygoscelid penguin at 4 different sites on the WAP to address 3 specific hypotheses: (1) species differ in the degree of breeding synchrony within a colony, (2) interannual variation in pygoscelid penguin breeding phenology (as measured by CIDs) reflects interannual variation in environmental conditions immediately prior to clutch initiation, and (3) species differ in their phenological plasticity, and these differences reflect a dichotomy between those that are resident and migrant in the non-breeding period. In the Discussion, we use these results to understand how differential breeding plasticity and synchrony may impact interspecific interactions under a climate change scenario.

\section{MATERIALS AND METHODS}

Clutch initiation data were taken from long-term studies of penguin colonies at 3 penguin breeding locations (Table 1, Fig. 1): Cape Shirreff, Livingston Island (62 $28^{\prime} \mathrm{S}, 60^{\circ} 46^{\prime} \mathrm{W}$; 1997-2006); Admiralty Bay, King George Island (62 ${ }^{\circ} 10^{\prime} \mathrm{S}, 58^{\circ} 30^{\prime} \mathrm{W}$; 1991-2006); and Humble Island (64 ${ }^{\circ} 46^{\prime} \mathrm{S}, 64^{\circ} 06^{\prime} \mathrm{W}$; 1991-2000). Breeding phenology data were collected according to the CCAMLR Ecosystem Monitoring Program (CEMP) Standard Methods (Standard Method 9; CCAMLR 2004). Additional data were used from a short-term study at Petermann Island $\left(65^{\circ} 10^{\prime} \mathrm{S}, 64^{\circ} 10^{\prime} \mathrm{W}\right.$; 
Table 1. Details of study sites and clutch initiation data. $n$ : range of clutch initiation dates (CIDs) recorded per year for each Species $\times$ Site combination (not including discarded CIDs; see 'Materials and methods' and Table S1 in the supplement at www.int-res.com/articles/suppl/m454p135_supp.pdf)

\begin{tabular}{|c|c|c|c|c|}
\hline Site & Species & Period & $\mathrm{n}$ & Source \\
\hline \multirow{2}{*}{$\begin{array}{l}\text { Admiralty Bay, } \\
\text { King George Island } \\
\left(62^{\circ} 10^{\prime} \mathrm{S}, 58^{\circ} 30^{\prime} \mathrm{W}\right)\end{array}$} & Adélie & 1991-2006 & 83-194 & $\begin{array}{l}\text { W.Z.T. \& S.G.T. } \\
\text { (unpubl. data) }\end{array}$ \\
\hline & Gentoo & 1991-2006 & $38-199$ & $\begin{array}{l}\text { W.Z.T. \& S.G.T. } \\
\text { (unpubl. data) }\end{array}$ \\
\hline \multirow{2}{*}{$\begin{array}{l}\text { Cape Shirreff, } \\
\text { Livingston Island } \\
\left(62^{\circ} 28^{\prime} \mathrm{S}, 60^{\circ} 46^{\prime} \mathrm{W}\right)\end{array}$} & Chinstrap & 1997-2006 & $57-99$ & W.Z.T. \& S.G.T. \\
\hline & Gentoo & $\begin{array}{c}1998-2004 \\
2006\end{array}$ & $23-53$ & $\begin{array}{l}\text { W.Z.T. \& S.G.T. } \\
\text { (unpubl. data) }\end{array}$ \\
\hline $\begin{array}{l}\text { Humble Island } \\
\left(64^{\circ} 46^{\prime} \mathrm{S}, 64^{\circ} 06^{\prime} \mathrm{W}\right)\end{array}$ & Adélie & $\begin{array}{l}1991-1996 \\
1999-2000\end{array}$ & $81-100$ & Fraser (2004) \\
\hline \multirow[t]{2}{*}{$\begin{array}{l}\text { Petermann Island } \\
\left(65^{\circ} 10^{\prime} \mathrm{S}, 64^{\circ} 10^{\prime} \mathrm{W}\right)\end{array}$} & Gentoo & $2005-2007$ & $92-99$ & $\begin{array}{l}\text { H.J.L., W.F.F. \& R.N. } \\
\text { (unpubl. data) }\end{array}$ \\
\hline & Adélie & 2005-2007 & $47-56$ & $\begin{array}{l}\text { H.J.L., W.F.F. \& R.N. } \\
\text { (unpubl. data) }\end{array}$ \\
\hline
\end{tabular}

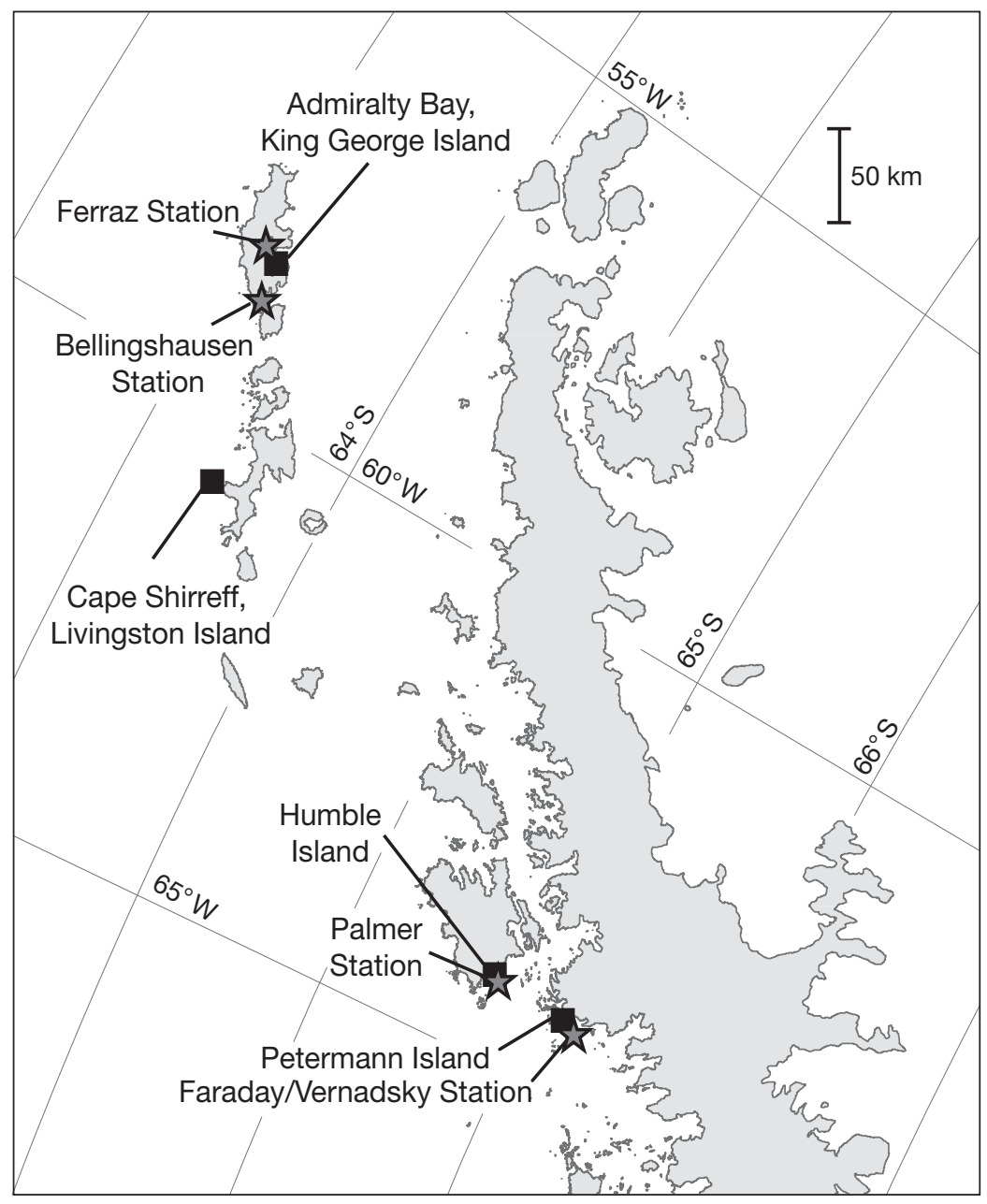

Fig. 1. The Antarctic Peninsula with sites (black squares) and weather stations (gray stars) used in this analysis
2005-2007); site details and field methods of the Petermann Island study may be found in Lynch et al. (2010). A total of 6108 CIDs were recorded. Of these, we discarded a small number (174) of CIDs because the first egg laid was not directly observed and CID had been inferred based on the timing of subsequent phenological events (e.g. second egg laid or first egg hatched). In all cases, new nests were chosen for observation each season, minimizing the potential for serial autocorrelation in CIDs.

We modeled mean clutch initiation (site $j$, year $t$ ) as a linear function of 3 a priori covariates - species (sp), latitude (lat) and year (measured relative to 2000) — and a suite of a posteriori environmental covariates. On the basis of previous studies reporting staggered breeding among sympatric pygoscelid penguins (e.g. Trivelpiece et al. 1987), we included species as a factor in our model. As latitudinal gradients have been found to be important in the breeding phenology of penguins (Warham 1972, Ainley 2002, Lynch et al. 2009) and other seabirds (Croxall 1984, Wanless et al. 2008), latitude was included as a covariate in the model. Year was included (as a fixed effect) to quantify any temporal trends in breeding phenology unaccounted for by trends in modeled environmental covariates. We considered 8 additional covariates representing various aspects of environmental conditions in the austral spring immediately prior to clutch initiation (August-October; Table 2). Monthly averages of mean air temperatures and sea-ice area were included for each of August, September and October. Both sea-surface temperature and monthly average Southern Oscillation Index were highly correlated between adjacent months and so a seasonal average (August-October) of these indices was used instead of separate monthly means. Models of CID at nest $i$, at site $j$, in year $t$ took the form: 
Table 2. Sources of environmental data considered in the model selection process.

\begin{tabular}{|c|c|}
\hline & Source \\
\hline \multicolumn{2}{|l|}{ Temperature } \\
\hline $\begin{array}{l}\text { King George Is. } \\
\text { Livingston Is. }\end{array}$ & Bellingshausen Stn (www.antarctica.ac.uk/met/gjma/) \\
\hline Petermann Is. & Vernadsky Stn (www.antarctica.ac.uk/met/gjma/) \\
\hline Humble Is. & Palmer Station (LTER archive ${ }^{a}$, http://pal.lternet.edu/) \\
\hline SST & $\begin{array}{l}\text { National Climatic Data Center Global Surface Tempera- } \\
\text { ture Anomalies Dataset (www.ncdc.noaa.gov/cmb-faq/ } \\
\text { anomalies.html) }\end{array}$ \\
\hline SOI & $\begin{array}{l}\text { University Center for Atmospheric Research Climate } \\
\text { Analysis Section Data Catalogue (www.cgd.ucar.edu/cas/ } \\
\text { catalog/climind/SOI.signal.ascii) }\end{array}$ \\
\hline Ice area & Palmer Station (LTER archive ${ }^{\mathrm{b}}$, http://pal.lternet.edu/) \\
\hline \multicolumn{2}{|c|}{$\begin{array}{l}{ }^{\mathrm{a}} \text { K. S. Baker (2008) Daily weather observations (air temperature, pressure, } \\
\text { wind, precipitation) starting in April } 1989\end{array}$} \\
\hline
\end{tabular}

where Eq. (1) links individual nest CID to population mean CID (meanCID) with a variance that depends on intraspecies breeding synchrony $\tau_{\mathrm{sp}[i]}^{2}$, and Eq. (2) links population mean CID to interannual variability in environmental conditions. The interaction between environmental conditions and species is included to account for potential differences in phenological response among the 3 pygoscelids. Note that empirical data for meanCID, and not model estimated meanCID from Eq. (2), are used in Eq. (1) to prevent error in Eq. (2) from inflating estimates of $\tau_{\mathrm{sp}[i]}^{2}$. All populationlevel mean CID data are given in Table S1 in the supplement at www.int-res.com/articles/suppl/m454p135_supp.pdf. Model parameters were given vague normal prior distributions and the precisions associated with model synchrony $\left(1 / \tau^{2}\right)$ and model error $\left(1 / \sigma^{2}\right)$ were given vague gamma distributions. Models were fit to the data using the software package WinBUGS (Spiegelhalter et al. 2003). We used a burn-in period of 1000 samples and drew our posterior distribution from the following 9000 samples in each of 3 overdispersed and randomly-initialized parallel Markov chain Monte Carlo chains. This was more than sufficient to achieve model convergence and adequate sampling of the posterior distribution. Models were compared using the deviance information criterion as described in Spiegelhalter et al. (2002).

\section{RESULTS}

There was overwhelming support for the model containing mean October temperature (Table 3). Mean October temperatures were significantly correlated with clutch initiation, and all 3 species showed an advanced schedule of breeding in response to warmer October temperatures (Table 4). CIDs were delayed 5 to $16 \mathrm{~d}$ in 1994 and 2002 because of unusually cold October temperatures ( $>2 \sigma$ below the 1944-2006 mean at Bellingshausen Station). Although all 3 species demonstrated some degree of plasticity in breeding phenology, as defined by interannual variation in clutch initiation in response to environmental conditions, we found

Table 3. Models for CID ranked by fit to data. pD: rough measure of the effective number of parameters (Spiegelhalter et al. 2002); DIC: deviance information criterion; $\Delta$ DIC: difference between each model and the best model; $w_{i}$ : model weight.

The null model contains no environmental covariates and is included for comparison. sp: species; lat: latitude

\begin{tabular}{|c|c|c|c|c|c|}
\hline Rank & Model: CID $\sim$ sp + lat + year + covariates $($ see below $) \times s p$ & $\mathrm{pD}$ & DIC & $\Delta \mathrm{DIC}$ & $w_{i}$ \\
\hline 1 & Mean October temperature & 18.1 & 32600.6 & 0 & $\sim 1.0$ \\
\hline 2 & Mean August temperature & 16.6 & 32641.1 & 40.5 & $<0.001$ \\
\hline 3 & August-October average Southern Oscillation Index & 17.7 & 32641.9 & 41.3 & $<0.001$ \\
\hline 4 & August ice area & 15.4 & 32642.3 & 41.7 & $<0.001$ \\
\hline 5 & August-October average sea surface temperature & 19.3 & 32644.3 & 43.7 & $<0.001$ \\
\hline 6 & October ice area & 13.6 & 32644.8 & 44.2 & $<0.001$ \\
\hline 7 & September ice area & 13.4 & 32646.0 & 45.4 & $<0.001$ \\
\hline 8 & Mean September temperature & 15.2 & 32647.7 & 47.1 & $<0.001$ \\
\hline 9 & (No environmental covariates) & 19.1 & 32649.3 & 48.7 & $<0.001$ \\
\hline
\end{tabular}


that gentoo penguins advanced breeding almost twice as much as either Adélies or chinstraps in response to warmer temperatures (Figs. 2 \& 3, Table $4)$. In addition to the effect of warmer October temperatures on CIDs, we found an overall trend towards earlier reproduction of $0.15 \pm 0.05 \mathrm{~d} \mathrm{yr}^{-1}$ (posterior mean $\pm 1 \mathrm{SD}$ ) over the period for which data were available (1991-2007). This trend was significant for all of the models compared (Table 3 ) and, therefore, cannot be explained by underlying trends in any of the covariates not included in the final model. As such, the cause of this additional advance in CIDs is unknown.

Both species and latitude were significantly correlated with CIDs. Pygoscelid penguins bred in a predictable sequence, with Adélie penguins being the first to arrive and lay eggs, followed by the gentoos and then the chinstraps (Table 4, Fig. 2). At Admiralty Bay, model predicted mean CIDs in 2000 (mean October temperature $=-2.0^{\circ} \mathrm{C}$ ) were 29 October, 3 November and 19 November for Adélies, gentoos and chinstraps, respectively. Sites further south (negative latitude relative to Admiralty Bay) had delayed CIDs relative to more northerly sites (Table 4).

We found different levels of intraseason breeding synchrony among the 3 pygoscelid species (Table 4), with chinstraps showing the most synchronous breeding $(\tau=2.7 \mathrm{~d})$, followed by Adélie penguins $(\tau=$ $3.6 \mathrm{~d})$ and then gentoo penguins $(\tau=4.2 \mathrm{~d})$. All pairwise differences in synchrony were statistically significant (Table 4). Despite containing only 4 variables, our model for clutch initiation explained a large proportion of the variability in observed mean CID at the 4 study sites $\left(r^{2}=0.74\right)$.

\section{DISCUSSION}

Despite strong similarities in breeding habitat, diet, clutch size and overall life history, breeding phenology is one niche axis along which the pygoscelid penguins are segregated. Our results provide strong evidence that climate change may significantly alter the absolute and relative timing of clutch initiation in these 3 species. Gentoo penguins are more asynchronous and demonstrate greater plasticity in breeding phenology than either Adélie or chinstrap penguins, with potential attendant consequences for interspecific interactions in mixed colonies.

There are compelling biological reasons why October temperatures might be expected to play a role in the timing of breeding of the 3 penguin species. All 3 study species at our study sites nest directly on rocks and breeding is conditional on the appearance of snow-free areas in October when penguins arrive to breed. Warm October temperatures hasten snow melt in breeding colonies and allow for earlier nest building and egg laying, although long-term trends in accumulation will reflect a balance between increased snow melt and changing patterns of precipitation (Thompson et al. 1994, Turner et al. 2005, Bracegirdle et al. 2008). Snow accumulation has been implicated as an important factor driving differential Adélie colony trends at the local (within-site) scale (Fraser \& Patterson 1997, Patterson et al. 2003, Bricher et al. 2008), and the importance of snow-free areas to inter-season variability in the timing of gentoo breeding has been suggested by Gwynn (1953). In an Arctic analog, Moe et al. (2009) found that egg laying in ground-nesting little auks was strongly

Table 4. Model parameters, their interpretation and estimates (mean $\pm 1 \mathrm{SD}$ of the posterior distribution). Clutch initiation dates (CIDs) are measured relative to 1 October (e.g. CID = 32 is 1 November), and latitude is measured relative to Admiralty Bay, King George Island (latitude is negative for sites further south). sp: species; lat: latitude; $\tau$ : standard deviation of intra-season intra-site breeding synchrony

\begin{tabular}{|llc|}
\hline Covariate & Interpretation of regression coefficient & Estimate \\
\hline sp [Adélie] & Baseline CID for Adélie penguins & $25.4 \pm 0.6 \mathrm{~d}$ \\
sp [gentoo] & Baseline CID for gentoo penguins & $27.6 \pm 0.9 \mathrm{~d}$ \\
sp [chinstrap] & Baseline CID for chinstrap penguins & $46.5 \pm 1.4 \mathrm{~d}$ \\
lat & Effect of latitude & $-5.2 \pm 0.2 \mathrm{~d} \mathrm{deg}^{-1}$ \\
Oct. temp. [Adélie] & Effect of mean Oct. temp. on CID for Adélie penguins & $-1.7 \pm 0.2 \mathrm{~d}^{\circ} \mathrm{C}^{-1}$ \\
Oct. temp. [gentoo] & Effect of mean Oct. temp. on CID for gentoo penguins & $-3.2 \pm 0.2 \mathrm{~d}^{\circ} \mathrm{C}^{-1}$ \\
Oct. temp. [chinstrap] & Effect of mean Oct. temp. on CID for chinstrap penguins & $-1.8 \pm 0.6 \mathrm{~d}{ }^{\circ} \mathrm{C}^{-1}$ \\
year & Overall trend in CID shared by all 3 species & $-0.15 \pm 0.05 \mathrm{~d}$ yr $\mathrm{r}^{-1}$ \\
$\tau$ [Adélie] & Within-site standard deviation of CID for Adélie penguins & $3.62 \pm 0.05 \mathrm{~d}$ \\
$\tau$ [gentoo] & Within-site standard deviation of CID for gentoo penguins & $4.16 \pm 0.06 \mathrm{~d}$ \\
$\tau$ [chinstrap] & Within-site standard deviation of CID for chinstrap penguins & $2.73 \pm 0.07 \mathrm{~d}$ \\
\hline
\end{tabular}



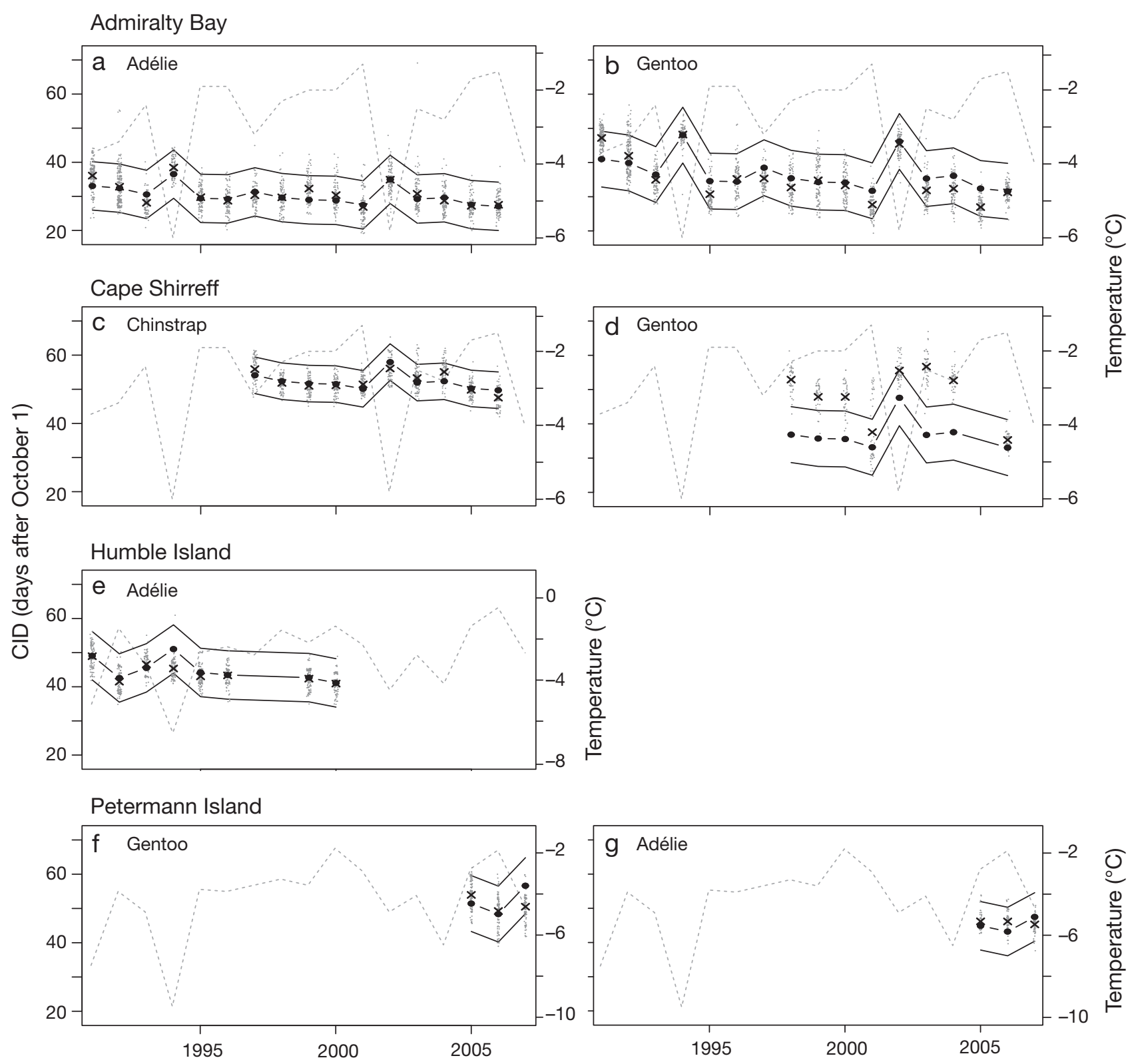

Fig. 2. Raw data and model results for (a) Adélie penguins at Admiralty Bay, (b) gentoo penguins at Admiralty Bay, (c) chinstrap penguins at Cape Shirreff, (d) gentoo penguins at Cape Shirreff, (e) Adélie penguins at Humble Island, (f) gentoo penguins at Petermann Island, (g) Adélie penguins at Petermann Island. The black solid circles and dashed lines represent the model estimate of the mean clutch initiation date (CID) and the solid lines above and below represent the mean CID $\pm 2 \tau$ $(\tau$ : standard deviation of intra-season breeding synchrony, see Table 4). Raw data are shown as gray dots (jittered for visual clarity) and the mean of the raw data indicated by black ' $x$ 's. Model fit can be assessed visually by comparing the mean CID predicted by the model (solid circles) with the mean of the raw CID data (black ' $x$ 's) and by comparing the separation between the upper and lower solid black lines with the temporal distribution of clutch initiation in the raw data (larger distribution = greater asynchrony in reproduction). October mean temperatures at Bellingshausen Station (a-d), Palmer Station (e) and Vernadsky Station $(f, g)$ are plotted with a gray dotted line (scale on right axis). Panel rows (top to bottom) are arranged geographically, north to south

determined by the appearance of snow-free nesting sites and, as a consequence, found breeding phenology to be correlated with spring air temperature. Significant topography-mediated microscale variability makes it difficult to extrapolate snow depth at individual colonies from measurements recorded at the nearest meteorological station. Air temperature, although just one influence on spring snow melt, represents a useful proxy for modeling breeding phenology across a large latitudinal gradient. 


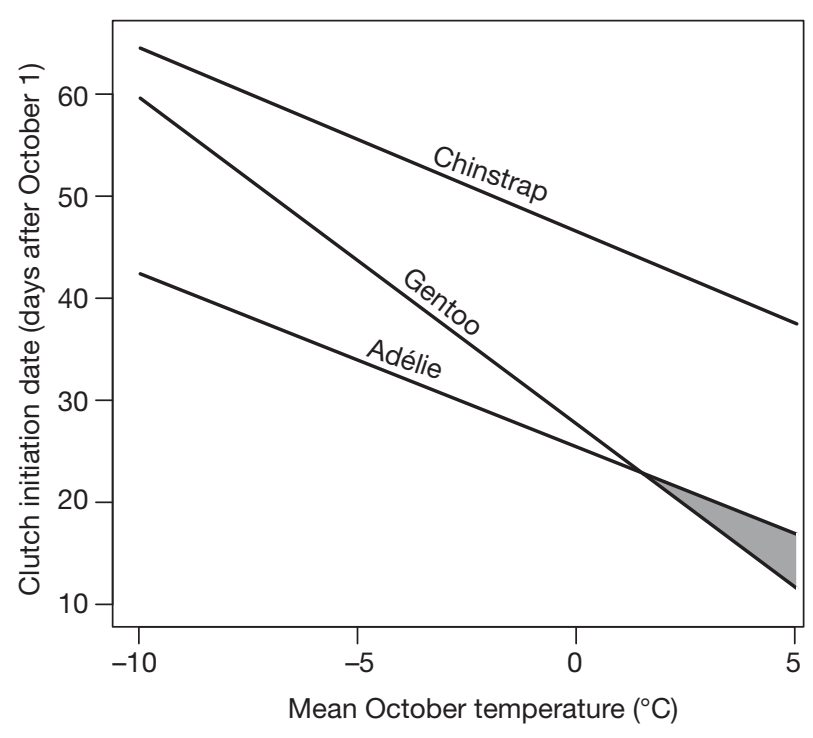

Fig. 3. Model-predicted clutch initiation dates (CIDs) for each species as a function of mean October temperature assuming a latitude equal to that at Admiralty Bay $\left(62^{\circ} 10^{\prime} \mathrm{S}\right)$ and the year 2000 . At temperatures above $1.5^{\circ} \mathrm{C}$, the mean CID for gentoos is predicted to occur before mean CID for Adélies by an amount represented by the gray shading

\section{Potential effects of shifting phenology on competition and coexistence}

In addition to being inshore feeders during the breeding season, gentoo penguins differ from Adélies and chinstraps by remaining in the waters near their breeding colonies throughout the austral winter (Wilson et al. 1998, Clausen \& Pütz 2003, Tanton et al. 2004). For this reason, gentoos can be considered resident species relative to Adélies and chinstraps, both of which can migrate long distances from the colony in the non-breeding months (Davis et al. 1996, Fraser \& Trivelpiece 1996, Trivelpiece et al. 2007, Ballard et al. 2010). The dichotomy between resident and migrant species is important in light of recent evidence that migrant species are often less able to respond appropriately to the phenological effects of climate change (Both \& Visser 2001, Both et al. 2006, Rubolini et al. 2010), leading to disproportionate impacts on migrant species that can alter competitive relationships between resident and migrant bird species breeding at the same location (Ahola et al. 2007). Gentoo penguins, foraging in inshore waters near the breeding colony prior to the breeding season, are in a position to experience and take advantage of a warm spring and early snow melt whereas Adélies and chinstraps must decide when to return to the colony without the benefit of local information on breeding conditions.
Although differential foraging habitat use during the breeding season (diving depth and distance to shore) may mitigate interspecific competition for prey (Trivelpiece et al. 1987, Lynnes et al. 2002, Kokubun et al. 2010, Wilson 2010), penguins breeding in mixed-species colonies must still compete for snow-free breeding territory (Trivelpiece \& Volkman 1979, Carlini et al. 2005). The average 2-day 'headstart' of Adélies over gentoos may not result in a significant temporal partitioning of prey resources during chick rearing, but it does allow Adélie penguins to establish nests in advance of the larger, and physically dominant, gentoo penguin. Gentoo penguins have been known to disturb adjacent Adélie penguins (H.J.L. \& R.N., pers. obs.) and Adélie penguins nesting in gentoo-dominated colonies (>80\% gentoo) have significantly lower reproductive success than those nesting in Adélie-dominated colonies (> $80 \%$ Adélie) (H.J.L. unpubl. data). Likewise, other studies have reported that chinstrap penguins usurp nests from younger, less experienced and latearriving Adélies, with adverse consequences on Adélie breeding success (Trivelpiece \& Volkman 1979, Trivelpiece et al. 1984, Carlini et al. 2005). Thus, staggered arrival and clutch initiation may allow Adélie penguin populations to persist at gentoo-dominated sites (e.g. Booth Island, Petermann Island).

Our results show that the higher phenological plasticity of the gentoo penguin compresses the headstart of the Adélie penguin in warm years, which suggests that Adélie penguin populations will be disadvantaged as the WAP continues to warm. This may be one explanation for why small Adélie populations breeding in mixed colonies with gentoo penguins have been declining precipitously in recent years (Lynch et al. 2008). This effect-a climate-induced compression of the interval between the onset of breeding in sympatric species - is known to increase competition between species competing for limited resources (Slagsvold 1975, Slagsvold 1976, Ahola et al. 2007). The resident species, in this case the gentoo penguin, is expected to have a significant advantage over its 2 migratory congeners.

\section{Breeding asynchrony and plasticity}

We did not track CIDs of individual penguins across years and, therefore, we cannot unequivocally distinguish between phenotypic plasticity in individual response and microevolutionary change as a result of natural selection (see discussion of this 
dichotomy in Gienapp et al. 2008, Visser 2008). However, the time scale over which local populations responded to environmental cues (i.e. annually) relative to the generation time $\left(8+\mathrm{yr}_{i}\right.$ Forcada \& Trathan 2009) suggests that phenotypic plasticity played at least some role in the phenological variability observed in the present study; these results are consistent with other studies suggesting the same (Przybylo et al. 2000, Charmantier et al. 2008, Tøttrup et al. 2008, see also Forcada \& Trathan 2009). Although population-level plasticity need not imply individual variability in phenotypic plasticity (Reed et al. 2006), there is evidence to suggest that individuals with more plasticity in breeding phenology may have a selective advantage over individuals less able to respond to local cues or environmental changes (Brommer et al. 2005, Nussey et al. 2005). However, highly synchronous colonial breeders derive many well-documented benefits from their synchrony (e.g. social foraging, reduced predation; Hoogland \& Sherman 1976, Birkhead 1977, Ims 1990, Hatchwell 1991) that may select against highly plastic (and potentially asynchronous) individuals (Reed et al. 2006). Although all 3 of the penguin species studied are phenologically limited by the short austral summer on the Antarctic Peninsula, our results found significant differences in breeding synchrony, with gentoo penguins being the least synchronous and chinstraps the most synchronous of the pygoscelids. Without the constraints imposed by the more highly synchronous breeding strategy of the Adélies and chinstraps, gentoo penguins may be more free to respond to environmental cues.

The extent to which individual variation in timing of breeding (i.e. early or late relative to environmental cues or the colony's mean breeding date) affects reproductive success and, ultimately, fitness is unknown, but early breeding has been associated with higher breeding success in pygoscelids (Bost \& Jouventin 1991, Viñuela et al. 1996) and other colonially nesting seabirds (Reed et al. 2006, 2009). Such differential breeding success would drive a population-level shift to earlier breeding even if individuals in a population showed a high degree of variability in phenological plasticity, although the strength of heritability in the timing of egg laying among pygoscelids remains unclear. On an interspecific level, we would expect that a species with a more plastic breeding phenology would be at an advantage over its less-plastic congeners, which is consistent with the rapid growth of gentoo penguin populations and sharp declines in Adélie and chinstrap populations where they overlap in the southern WAP
(Ducklow et al. 2007, Lynch et al. 2008). The optimum balance between the advantages of plasticity in response to a changing climate and the advantages of breeding synchrony will differ across the wide environmental gradient inhabited by each of the 3 penguin species, but the rapidity of change on the WAP will likely tip the balance in favor of individuals, populations and species capable of adapting quickly.

\section{Role of sympatric associations on breeding phenology}

Despite broad agreement between the model and the data, our model fit poorly for gentoo penguins breeding at Cape Shirreff (Fig. 2d). If we removed gentoos at Cape Shirreff from consideration, the fit of mean predicted CID to the observed mean CID improved considerably $\left(\mathrm{r}^{2}\right.$ increases from 0.74 to 0.94). Gentoos at Cape Shirreff bred $14.8 \mathrm{~d}$ on average (and up to $25.9 \mathrm{~d}$ ) later than gentoos only $130 \mathrm{~km}$ away at Admirality Bay (a difference nearly equal to the $\sim 16 \mathrm{~d}$ gentoo laying period; Trivelpiece et al. 1987) and $19.9 \mathrm{~d}$ on average later than predicted by the model. One important difference between these 2 sites is the different sympatric associations involved. At Admirality Bay, gentoos breed alongside Adélie penguins, which are the earliest to breed of the 3 pygoscelid penguins, but at Cape Shirreff, gentoos breed alongside chinstrap penguins, which are the last of the 3 species to initiate breeding. It has been hypothesized that the staggered breeding of the pygoscelid penguins is a byproduct of dissimilar sea ice tolerances as reflected in the typical sea ice phenology of their disparate but overlapping ranges (Trivelpiece et al. 1987, Fraser et al. 1992). An alternative explanation is that staggered breeding facilitates the temporal partitioning of prey resources (Lishman 1985). The former explanation would predict no difference in the breeding phenology of gentoos at these 2 sites; therefore, our results are inconsistent with this explanation. In contrast, competitive interactions would predict that gentoos that breed at Cape Shirreff would breed earlier than gentoos at Admiralty Bay, but this is opposite of what we found. Neither of these explanations is consistent with the phenological differences between these 2 sites. A third possibility is that enhanced interspecific synchrony might be advantageous for predator swamping (Ims 1990). Gentoos may benefit from timing their breeding in synchrony with other penguins so as to minimize adult mortality by leopard seals 
(Hydrurga leptonyx) and egg and chick mortality by skuas (Catharacta spp.). Actively brooding neighbors are also less likely to flush off the nest when disturbed and are thus less likely to trample or otherwise interfere with incubation than pre-breeders or non-breeders (Murphy \& Schauer 1996). These hypotheses are currently being investigated.

\section{Long-term forecasts}

Current climate models for the Antarctic Peninsula predict a continued shift towards warmer and wetter conditions (Meehl et al. 2007). Our study of phenological responses to interannual variation imply that continued warming will cause additional advances in breeding phenology for all 3 pygoscelid species until gains are balanced by increased early spring snow (Thompson et al. 1994), temporal mismatches with prey resources (Trivelpiece et al. 1987), or physiological constraints of light or pre-season body condition (e.g. Ainley 2002). Although mean October air temperature explained much of the interannual variation in CIDs, the remaining trend of earlier laying $(0.15 \pm$ $0.05 \mathrm{~d} \mathrm{yr}^{-1}$ ) shared by all 3 species requires further investigation. Uncertainties regarding future climate change scenarios preclude long-term forecasts of breeding phenology on the WAP, although future efforts to understand population-wide changes should consider the potential role of shifting breeding phenologies and the effect such shifts may have on interspecific competition for resources.

Acknowledgements. H.J.L., W.F.F. and R.N. gratefully acknowledge assistance from the US National Science Foundation Office of Polar Programs (award no. NSF/OPP0739515). Data from the Palmer LTER data archive were supported by Office of Polar Programs, NSF/OPP-9011927, NSF/OPP-9632763 and NSF/OPP-0217282.

\section{LITERATURE CITED}

Ahola MP, Laaksonen T, Eeva T, Lehikoinen E (2007) Climate change can alter competitive relationships between resident and migratory birds. J Anim Ecol 76:1045-1052

Ainley DG (2002) The Adélie penguin. Columbia University Press, New York, NY

Ballard G, Toniolo V, Ainley DG, Parkinson CL, Arrigo KR, Trathan PN (2010) Responding to climate change: Adélie penguins confront astronomical and ocean boundaries. Ecology 91:2056-2069

> Barbraud C, Weimerskirch H (2006) Antarctic birds breed later in response to climate change. Proc Natl Acad Sci USA 103:6248-6251

Birkhead TR (1977) The effect of habitat and density on breeding success in the Common Guillemot (Uria aalge).
J Anim Ecol 46:751-764

Bost CA, Jouventin P (1990) Evolutionary ecology of gentoo penguins (Pygoscelis papua). In: Davis LS, Darby JT (eds) Penguin biology. Academic Press, New York, NY, p 85-112

Bost CA, Jouventin P (1991) The breeding performance of the gentoo penguin Pygoscelis papua at the northern edge of its range. Ibis 133:14-25

> Both C, Visser ME (2001) Adjustment to climate change is constrained by arrival date in a long-distance migrant bird. Nature 411:296-298

> Both C, Artemyev AV, Blaauw B, Cowie RJ and others (2004) Large-scale geographical variation confirms that climate change causes birds to lay earlier. Proc R Soc Lond B 271: 1657-1662

Both C, Bouwhuis S, Lessells CM, Visser ME (2006) Climate change and population declines in a long-distance migratory bird. Nature 441:81-83

Bracegirdle TJ, Connolley WM, Turner J (2008) Antarctic climate change over the twenty first century. J Geophys Res 113:D03103 doi:10.102912007JD008933

Bricher PK, Lucieer A, Woehler EJ (2008) Population trends of Adélie penguin (Pygoscelis adeliae) breeding colonies: a spatial analysis of the effects of snow accumulation and human activities. Polar Biol 31:1397-1407

Brommer JE, Merilä J, Sheldon BC, Gustafsson L (2005) Natural selection and genetic variation for reproductive reaction norms in a wild bird population. Evolution 59: 1362-1371

Brown JL, Li S, Bhagabati N (1999) Long-term trend toward earlier breeding in an American bird: a response to global warming. Proc Natl Acad Sci USA 96:5565-5569

Carlini AR, Coria NR, Santos MM, Buján SM (2005) The effect of chinstrap penguins on the breeding performance of Adélie penguins. Folia Zool 54:147-158

CCAMLR (Commission for the Conservation of Antarctic Marine Living Resources) (2004) CCAMLR Ecosystem Monitoring Program (CEMP) standard methods. CCAMLR, Hobart, Australia

> Chadwick EA, Slater FM, Ormerod SJ (2006) Inter- and intraspecific differences in climatically mediated phenological change in coexisting Triturus species. Glob Change Biol 12:1069-1078

Charmantier A, McCleery RH, Cole LR, Perrins C, Kruuk LEB, Sheldon BC (2008) Adaptive phenotypic plasticity in response to climate change in a wild bird population. Science 320:800-803

Clarke A, Murphy EJ, Meredith MP, King JC, Peck LS, Barnes DKA, Smith RC (2007) Climate change and the marine ecosystem of the western Antarctic Peninsula. Philos Trans R Soc Lond B 362:149-166

Clausen A, Pütz K (2003) Winter diet and foraging range of gentoo penguins (Pygoscelis papua) from Kidney Cove, Falkland Islands. Polar Biol 26:32-40

- Crick HQP, Sparks TH (1999) Climate change related to egg-laying trends. Nature 399:423-424

Croxall JP (1984) Seabirds. In: Laws RM (ed) Antarctic ecology, Vol 2. Academic Press, New York, p. 533-616

Croxall JP, Prince PA (1980) Food, feeding ecology and ecological segregation of seabirds at South Georgia. Biol J Linn Soc 14:103-131

Croxall JP, Trathan PN, Murphy EJ (2002) Environmental change and Antarctic seabird populations. Science 297: 1510-1514

Davis LS, Boersma PD, Court GS (1996) Satellite telemetry 
of the winter migration of Adélie penguins (Pygoscelis adeliae). Polar Biol 16:221-225

Ducklow HW, Baker K, Martinson DG, Quetin LB and others (2007) Marine pelagic ecosystems: the West Antarctic Peninsula. Philos Trans R Soc Lond B 362:67-94

Forcada J, Trathan PN (2009) Penguin responses to climate change in the Southern Ocean. Glob Change Biol 15: 1618-1630

Forcada J, Trathan PN, Reid K, Murphy EJ, Croxall JP (2006) Contrasting population changes in sympatric penguin species in association with climate warming. Glob Change Biol 12:411-423

Fraser WR (2004) Adélie penguin breeding success and chronology studies. Palmer Station Antarctica LTER, available at http://pal.lternet.edu/data/ (study data set 'adbreed')

Fraser WR, Patterson DL (1997) Human disturbance and long-term changes in Adelie penguin populations: a natural experiment at Palmer Station, Antarctic Peninsula. In: Battaglia B, Valencia J, Walton DWH (eds) Antarctic communities: species, structure, and survival. Cambridge University Press, Cambridge, UK, p 445-452

Fraser WR, Trivelpiece WZ (1996) Factors controlling the distribution of seabirds: winter-summer heterogeneity in the distribution of Adélie penguin populations. In: Ross RM, Hofmann EE, Quetin LB (eds) Foundations for ecological research west of the Antarctic Peninsula. Antarctic Research Series 70. American Geophysical Union, Washington, DC, p 257-272

Fraser WR, Trivelpiece WZ, Ainley DG, Trivelpiece SG (1992) Increases in Antarctic penguin populations: reduced competition with whales or a loss of sea ice due to environmental warming? Polar Biol 11:525-531

Gienapp P, Teplitsky C, Alho JS, Mills JA, Merilä J (2008) Climate change and evolution: disentangling environmental and genetic responses. Mol Ecol 17:167-178

Gwynn AM (1953) The egg-laying and incubation periods of rockhopper, macaroni and gentoo penguins. Antarctic Division, Department of External Affairs, Melbourne

> Hatchwell BJ (1991) An experimental study of the effects of timing of breeding on the reproductive success of common guillemots (Uria aalge). J Anim Ecol 60:721-736

Hoogland JL, Sherman PW (1976) Advantages and disadvantages of bank swallow (Riparia riparia) coloniality. Ecol Monogr 46:33-58

Ims RA (1990) On the adaptive value of reproductive synchrony as a predator-swamping strategy. Am Nat 136: 485-498

Kokubun N, Takahashi A, Mori Y, Watanabe S, Shin HC (2010) Comparison of diving behavior and foraging habitat use between chinstrap and gentoo penguins breeding in the South Shetland Islands, Antarctica. Mar Biol 157: 811-825

Lishman GS (1985) The comparative breeding biology of Adélie and chinstrap penguins Pygoscelis adeliae and $P$. antarctica at Signy Island, South Orkney Islands. Ibis 127:84-99

Lynch HJ, Naveen R, Fagan WF (2008) Censuses of penguins, blue-eyed shags, and southern giant petrel populations in the Antarctic peninsula, 2001-2007. Mar Ornithol 36:83-97

Lynch HJ, Fagan WF, Naveen R, Trivelpiece SG, Trivelpiece WZ (2009) Timing of clutch initiation in Pygoscelis penguins on the Antarctic Peninsula: towards an improved understanding of off-peak census correction factors. CCAMLR Sci 16:149-165

Lynch HJ, Fagan WF, Naveen R (2010) Population trends and reproductive success at a frequently visited penguin colony on the western Antarctic Peninsula. Polar Biol 33: 493-503

Lynnes AS, Reid K, Croxall JP, Trathan PN (2002) Conflict or co-existence? Foraging distribution and competition for prey between Adélie and chinstrap penguins. Mar Biol 141:1165-1174

Meehl GA, Stocker TF, Collins WD, Friedlingstein AT and others (2007) Global climate projections. In: Solomon S, Qin D, Manning M, Chen Z and others (eds) Climate change 2007: the physical science basis. Contribution of Working Group I to the Fourth Assessment Report of the Intergovernmental Panel on Climate Change. Cambridge University Press, New York, NY, p 747-846

Moe B, Stempniewicz L, Jakubas D, Angelier F and others (2009) Climate change and phenological responses of two seabird species breeding in the high-Arctic. Mar Ecol Prog Ser 393:235-246

> Murphy EC, Schauer JH (1996) Synchrony in egg-laying and reproductive success of neighboring common murres, Uria aalge. Behav Ecol Sociobiol 39:245-258

Nussey DH, Postma E, Gienapp P, Visser ME (2005) Selection on heritable phenotypic plasticity in a wild bird population. Science 310:304-306

> Parmesan C (2006) Ecological and evolutionary responses to recent climate change. Annu Rev Ecol Syst 37: $637-669$

Patterson DL, Easter-Pilcher A, Fraser WR (2003) The effects of human activity and environmental variability on longterm changes in Adélie penguin populations at Palmer Station, Antarctica. In: Huiskes AHL, Gieskes WWC, Rozema J, Schorno RML, van der Vies SM, Wolff WJ (eds) Antarctic biology in a global context. Backhuys Publishers, Leiden, p 301-307

> Przybylo R, Sheldon BC, Merilä J (2000) Climatic effects on breeding and morphology: evidence for phenotypic plasticity. J Anim Ecol 69:395-403

Reed TE, Wanless S, Harris MP, Frederiksen M, Kruuk LEB, Cunningham EJA (2006) Responding to environmental change: plastic responses vary little in a synchronous breeder. Proc R Soc Lond B 273:2713-2719

> Reed TE, Warzybok P, Wilson AJ, Bradley RW, Wanless S, Sydeman WJ (2009) Timing is everything: flexible phenology and shifting selection in a colonial seabird. J Anim Ecol 78:376-387

Rubolini D, Saino N, Moller AP (2010) Migratory behavior constrains the phenological response of birds to climate change. Clim Res 42:45-55

Sander M, Balbao TC, Costa ES, dos Santos CR, Petry MV (2007) Decline in the breeding population of Pygoscelis antarctica and Pygoscelis adeliae on Penguin Island, South Shetland, Antarctica. Polar Biol 30:651-654

Schaefer T, Ledebur G, Beier J, Leisler B (2006) Reproductive responses of two related coexisting songbird species to environmental changes: global warming, competition, and population sizes. J Ornithol 147:47-56

> Slagsvold T (1975) Competition between the great tit Parus major and the pied flycatcher Ficedula hypoleuca in the breeding season. Ornis Scand 6:179-190

Slagsvold T (1976) Annual and geographical variation in the timing of breeding of the great tit Parus major and the pied flycatcher Ficedula hypoleuca in relation to envi- 
ronmental phenology and spring temperature. Ornis Scand 7:127-145

Smith RC, Stammerjohn SE (2001) Variations of surface air temperature and sea-ice extent in the western Antarctic Peninsula region. Ann Glaciol 33:493-500

Spiegelhalter DJ, Best NG, Carlin BP, van der Linde A (2002) Bayesian measures of model complexity and fit. J R Stat Soc B 64:583-639

Spiegelhalter DJ, Best NG, Carlin BP, van der Linde A (2003) WinBUGS version 1.4 user manual. Available at www.mrc-bsu.cam.ac.uk/bugs

Tanton JL, Reid K, Croxall JP, Trathan PN (2004) Winter distribution and behaviour of gentoo penguins Pygoscelis papua at South Georgia. Polar Biol 27:299-303

Thompson LG, Peel DA, Mosley-Thompson E, Mulvaney R and others (1994) Climate since A.D. 1510 on Dryer Plateau, Antarctic Peninsula: evidence for recent climate change. Ann Glaciol 20:420-426

Tøttrup AP, Thorup K, Rainio K, Yosef R, Lehikoinen E, Rahbek C (2008) Avian migrants adjust migration in response to environmental conditions en route. Biol Lett 4:685-688

Trathan PN, Forcada J, Murphy EJ (2007) Environmental forcing and Southern Ocean marine predator populations: effects of climate change and variability. Philos Trans R Soc Lond B 362:2351-2365

Trivelpiece W, Volkman NJ (1979) Nest-site competition between Adélie and chinstrap penguins: an ecological interpretation. Auk 96:675-681

Trivelpiece WZ, Trivelpiece SG, Volkman NJ (1984) Further insights into nest-site competition between Adélie and chinstrap penguins. Auk 101:882-884

> Trivelpiece WZ, Trivelpiece SG, Volkman NJ (1987) Ecological segregation of Adélie, gentoo, and chinstrap penguins at King George Island, Antarctica. Ecology 68:351-361

Trivelpiece WZ, Buckelew S, Reiss C, Trivelpiece SG (2007) The winter distribution of chinstrap penguins from two

Submitted: December 3, 2010; Accepted: June 9, 2011 breeding sites in the South Shetland Islands of Antarctica. Polar Biol 30:1231-1237

Turner J, Lachlan-Cope T, Colwell S, Marshall GJ (2005) A positive trend in western Antarctic Peninsula precipitation over the last 50 years reflecting regional and Antarctic-wide atmospheric circulation changes. Ann Glaciol 41:85-91

- Van der Putten WH, Macel M, Visser ME (2010) Predicting species distribution and abundance responses to climate change: why it is essential to include biotic interactions across trophic levels. Philos Trans R Soc Lond B 365: 2025-2034

Vaughan DG, Marshall GJ, Connolley WM, Parkinson C and others (2003) Recent rapid regional climate warming on the Antarctic Peninsula. Clim Change 60:243-274

Viñuela J, Moreno J, Carrascal LM, Sanz JJ and others (1996) The effect of hatching date on parental care, chick growth, and chick mortality in the chinstrap penguin Pygoscelis antarctica. J Zool 240:51-58

> Visser ME (2008) Keeping up with a warming world; assessing the rate of adaptation to climate change. Proc R Soc Lond B 275:649-659

- Visser ME, Both C (2005) Shifts in phenology due to global climate change: the need for a yardstick. Proc R Soc Lond B 272:2561-2569

Wanless S, Harris MP, Lewis S, Frederiksen M, Murray S (2008) Later breeding in northern gannets in the eastern Atlantic. Mar Ecol Prog Ser 370:263-269

Warham J (1972) Breeding seasons and sexual dimorphism in rockhopper penguins. Auk 89:86-105

Wilson RP (2010) Resource partitioning and niche hyper-volume overlap in free-living pygoscelid penguins. Funct Ecol 24:646-657

Wilson RP, Alvarrez B, Latorre L, Adelung D, Culik B, Bannasch R (1998) The movements of gentoo penguins Pygoscelis papua from Ardley Island, Antarctica. Polar Biol 19:407-413

Proofs received from author(s): September 12, 2011 